\title{
Discursos eleitorais para políticas governamentais de saúde nas duas cidades mais populosas do Brasil
}

\author{
Electoral discourses for governmental health policies in the two most \\ populous cities in Brazil
}

Marcelo Rocha Garcia', Alcides Silva de Miranda1

DOI: 10.1590/0103-1104201912007

RESUMO Quais seriam os tipos de discursos eleitorais para o setor de saúde registrados por candidaturas para governos municipais? Para investigar essa questão, realizou-se estudo qualitativo com análise hermenêutica de documentos programáticos eleitorais, registrados por candidaturas majoritárias no primeiro turno das eleições municipais de 2016, nas metrópoles brasileiras de São Paulo (SP) e do Rio de Janeiro (RJ). Na maioria dos discursos, não havia a descrição de estratégias institucionais específicas para a saúde, muito menos os seus termos de viabilidade e factibilidade. Evidenciaram-se quatro pretensões discursivas distintas, nas quais as proposições para políticas de saúde ou estavam reduzidas ao aspecto gerencial ou subsumidas a lugares-comuns discursivos. Contextualmente, evidenciou-se a ênfase em discursos normativos e apelos performáticos, sem consubstanciação em discursos práticos.

PALAVRAS-CHAVES Políticas públicas de saúde. Programas governamentais. Comportamento verbal. Fala.

\begin{abstract}
What would the types of electoral speeches be for the health sector registered by applications to municipal governments? To investigate this issue, a qualitative study was carried out with a hermeneutical analysis of electoral program documents, registered by majority candidates in the first round of the municipal elections of 2016 in the Brazilian metropolises of São Paulo (SP) and Rio de Janeiro (RJ). In most of the speeches there was no description of specific institutional strategies for health, much less its terms of viability and feasibility. Four distinct discursive profiles were emphasized, in which the propositions for health policies were either reduced to the managerial aspect or subsumed by discursive commonplaces. Contextually, there was an emphasis on normative discourses and performative appeals, without consubstantiation in practical discourses.
\end{abstract}

KEYWORDS Public health policy. Government programs. Verbal behavior. Speech. 


\section{Introdução}

A cada período eleitoral, as coligações e os partidos políticos em disputa apresentam propostas, promessas e programas de governo no intuito de persuadir os eleitores e angariar votos. Geralmente, nas disputas eleitorais, os candidatos buscam realçar as questões que têm maior apelo para a chamada 'opinião pública'. Por exemplo, as questões relacionadas aos problemas de saúde tendem a ser enfatizadas discursivamente com destaque.

Com efeito, os problemas de saúde têm sido reiteradamente manifestados como prioritários para as ações governamentais. Por exemplo, em 2014, um levantamento de opiniões realizado pelo Instituto Datafolha revelou que para $57 \%$ dos brasileiros o setor de saúde deveria ser definido como prioritário para as ações do governo federal, com larga vantagem proporcional em relação aos outros setores governamentais citados (educação, segurança pública, transportes etc.) ${ }^{1}$.

De modo genérico, os discursos eleitorais acerca de políticas públicas e governamentais têm sido estudados e analisados por inúmeros autores. Há muitos estudos publicados nos quais são analisados especificamente as formas e os conteúdos discursivos eleitorais, a partir de métodos típicos das ciências sociais ${ }^{2-5}$. Também existem publicações que versam sobre análises contextuais e teóricas acerca dos discursos e os processos eleitorais ${ }^{6-11}$.

Apesar dos discursos e processos eleitorais serem contemporaneamente muito pesquisados e analisados no campo das ciências sociais (notadamente, das ciências políticas), têm sido escassas as publicações nas quais esta temática se associa mais especificamente com a área da saúde ${ }^{12,13}$. No estudo relatado neste artigo, busca-se enfatizar tal associação, a partir da análise de discursos eleitorais registrados em programas de governo, por ocasião das eleições municipais nas duas maiores cidades brasileiras - São Paulo (SP) e Rio de Janeiro (RJ) -, no ano de 2016.

A análise de programas eleitorais de governo e, principalmente, dos discursos ali proferidos pode ser feita a partir de diversos e distintos referenciais teóricos e escopos metodológicos. Uma das formas possíveis leva em conta o discernimento teórico acerca de categorias discursivas, assim como de suas caracterizações em termos de competências discursivas e ações sociais correlatas.

Evidentemente, há distinções significativas entre teorias que versam sobre tipos de racionalidades, de competências e de (inter)ações sociais. Desde as importantes contribuições teóricas de Max Weber, de Talcott Parsons, de Jürgen Habermas e de outros autores, as análises de modalidades de comunicações e de discursos requerem referenciamentos categoriais distintivos. No Brasil, Rivera ${ }^{14}$ realizou uma revisão seminal sobre as distinções e aplicabilidades de teorias de ação racional, com ênfase na análise das diferenças entre o agir estratégico e o agir comunicativo.

A pretensão de análise neste estudo, embora referida genericamente às teorias da ação racional, está referenciada especificamente em uma categoria teórica. No caso do enfoque e da análise em questão, a referência teórica primordial é a de 'discurso prático'. Segundo Jürgen Habemas ${ }^{15}$, há discursos teóricos e normativos nos quais se intenta fundamentar as pretensões sobre as ações sociais, as prescrições sobre a realidade e as idealizações sobre o devir. Quando se trata de discursos teóricos e normativos, todas as expectativas de validade ficam suspensas até que suas afirmações problematizadas sejam confirmadas, legitimadas ou refutadas. Para o mesmo autor, há, ainda, os discursos práticos, que são proferimentos de caráter mais regulatório, mais afeitos aos termos da aplicabilidade, viabilidade, factibilidade e eficácia das normas preconizadas ou das prescrições no mundo real, nas relações cotidianas. Tais discursos práticos podem evidenciar contradições e/ou convergências com validações consensuais e modos de legitimação para determinadas normas problematizadas. Tal discernimento pode ser útil para a análise de discursos eleitorais porque os mesmos tenderiam a ter um caráter ambivalente, ou 
seja, seriam discursos teóricos e normativos porque deveriam apresentar prescrições sobre políticas, estratégias e ações governamentais futuras; seriam, também, discursos práticos porque deveriam apresentar os termos de viabilidade, aplicabilidade, factibilidade e eficácia de tais prescrições (proposições de políticas e estratégias governamentais).

Também é importante distinguir as racionalidades, competências discursivas e suas decorrências como ações sociais, de acordo com os propósitos que orientam a prática dos agentes/ atores sociais/institucionais. Mesmo que tal distinção sirva apenas para as análises parciais, uma vez que, na prática, ocorrem combinações e interveniências entre tais competências e (inter)ações sociais. Para efeito de referencial teórico para a análise adotada neste estudo, as racionalidades, competências e ações sociais podem ser caracterizadas assim ${ }^{16}$ :

- Normativas: orientadas para o reconhecimento, a indução e a observância de uma expectativa generalizada de comportamentos regrados, em razão de um consenso normativo prévio sobre ideações e valores compartilhados;

- Instrumentais (ou Teleológicas): orientadas para o êxito, com a decisão sobre opções instrumentais entre alternativas de ações, a partir de uma interpretação do contexto em que ocorrem;

- Estratégicas: também orientadas para o êxito ou a maximização de resultados, mas providas de cálculos racionais precedentes, que consideram a análise da situação em foco e curso, bem como as expectativas com relação aos meios e recursos de poder a serem utilizados, aos cenários futuros, aos percursos e aos movimentos dos agentes em sua interação política;

- Dramatúrgicas: orientadas para a adequação a normas comportamentais, expressas em (auto)encenações e representações recíprocas, que regulam a revelação de parte de cada subjetividade, de cada disposição interna, de cada vivência, de desejos e sentimentos pessoais;

- Comunicativas: orientadas para o entendimento, que são convicções linguisticamente mediadas, firmadas intersubjetivamente, a partir de motivações racionais quanto a princípios, valores e normas, bem como em relação aos objetivos almejados e aos meios para alcançá-los.

Nos discursos eleitorais, dados o propósito persuasivo e o caráter concorrencial, seria natural a ênfase dramatúrgica e performática, todavia, em se tratando de propostas governamentais, também seria esperado o exercício discursivo de ênfase normativa (proposições de diretrizes) e instrumental (razões práticas sobre métodos e termos de viabilidade, aplicabilidade e factibilidade para as proposições políticas e estratégicas).

Em relação ao presente estudo, a análise sobre determinados discursos eleitorais, que versam sobre proposições de políticas ou estratégias governamentais e de âmbito municipal para o setor de saúde, pode favorecer uma melhor compreensão acerca da lógica de significados para o fenômeno em questão - as eleições municipais e a questão da saúde -, como, também, para uma hermenêutica de sentido contextual acerca do processo eleitoral e de uma determinada 'cultura eleitoral' ou 'senso comum' eleitoral, pelo menos, no que diz respeito às duas metrópoles em foco.

\section{Aspectos metodológicos}

Estudo com abordagem qualitativa e análise hermenêutica de documentos programáticos sobre políticas governamentais de saúde registrados formalmente por candidaturas majoritárias no primeiro turno das eleições municipais de 2016, em duas metrópoles brasileiras, São Paulo (SP) e Rio de Janeiro (RJ). 
Para a amostragem intencional, selecionaram-se os processos eleitorais em primeiro turno ocorridos nos municípios supracitados, em razão de sua magnitude (maior número de candidaturas e coligações, maior eleitorado, cidades mais populosas do País, maiores orçamentos municipais etc.), relevância e pela melhor facilidade de acesso aos substratos discursivos produzidos.

Os documentos programáticos foram obtidos a partir de fontes secundárias de domínio público, tendo sido disponibilizados em mídia virtual pelo Tribunal Superior Eleitoral (TSE) (http://divulgacandcontas.tse. jus.br/divulga/). Trataram-se de 22 programas eleitorais das candidaturas majoritárias (11 de cada cidade) para os cargos de prefeito(a).

A partir do processamento do material empírico, adotaram-se as seguintes perspectivas de análise hermenêutica ${ }^{17}$ :

- Perspectiva de horizonte: esforço de apreensão prévia e contextualização de sentido para os conteúdos temáticos singulares e particulares identificados a partir dos discursos. Correspondente a uma hermenêutica inicial, com contextualização conceitual, histórica e política abrangente acerca de processos eleitorais e de democracia representativa no Brasil.

- Perspectiva circular: esforço de compreensão, a partir de um movimento em espiral, em busca de pressuposições e associações entre os conteúdos temáticos discursivos. Correspondente a leituras múltiplas e exaustivas com propósito de identificação de sintagmas analíticos.

- Perspectiva de diálogo: esforço de interlocução e compreensão a partir de diálogos com os discursos teóricos e práticos elaborados. Análise e diálogos teóricos em busca da compreensão de sentido para os discursos e processos eleitorais em questão.

- Perspectiva de mediação: análise a partir de referenciamento para com a categoria habermasiana de discursos práticos ${ }^{16}$ e elaboração de esquemas interpretativos acerca de pretensões discursivas.

Conforme antecipado, a categoria habermasiana de 'discursos práticos' $\mathbf{1 4}$ é o referencial utilizado para a tipificação das pretensões discursivas analisadas (eleitorais). Ou seja, mesmo que as pretensões eleitorais anunciadas possam ser caracterizadas por seu teor normativo, em busca de legitimação e validação (no caso eleitoral, não se trataria de validação consensual, mas de maioria ocasional), em tese, elas requerem a consubstanciação (também discursiva) em termos de sua aplicabilidade, viabilidade, factibilidade e eficácia. Tal requerimento de consubstanciação discursiva foi analisado.

Em termos procedimentais, foram adotados componentes do modelo de integração de lógicas para análise hermenêutica e dialética preconizado por Testa ${ }^{\mathbf{1 8}}$, a partir de: uma lógica extensiva, com ênfase na descrição de fatos (análise documental); uma lógica intensiva, com ênfase na explicação de significados dos discursos; e uma lógica hermenêutica, com ênfase na compreensão de um sentido contextual.

De acordo com a Resolução n ${ }^{0} 510 / 2016$, do Conselho Nacional de Saúde, por se tratar da obtenção, do manejo e da utilização de material textual oriundo exclusivamente de fontes de domínio público, não houve necessidade de submissão do respectivo projeto de estudo a um Comitê de Ética em Pesquisa (CEP).

\section{Descrição dos principais resultados}

A seguir, estão descritos sumariamente os aspectos considerados mais relevantes em termos de caracterização de elementos factuais (lógica extensiva) e de explicação de significados (lógica intensiva).

$\mathrm{Na}$ análise documental sobre os programas de governo registrados e disponibilizados pelo TSE, buscou-se aferir a existência e conferir 
a consistência de formulações textuais acerca de aspectos normativos considerados característicos para justificativas e proposições de políticas e estratégias governamentais. A predefinição desses itens levou em conta uma análise contextual prévia, em perspectiva eleitoral, na qual se considerou imprescindível o proferimento de discursos práticos com termos de aplicabilidade, viabilidade, factibilidade e eficácia, ainda que sob expectativas de legitimação (pela maioria de votos) e delegação de poder governamental. Ou seja, esperava-se que os discursos contidos nos documentos programáticos para políticas governamentais devessem estabelecer análises contextuais e setoriais (no caso, de saúde), marcos referenciais normativos (como concepções de princípios e diretrizes de ações); proposições estratégicas (sociais, institucionais, administrativas, programáticas); análises e proposições de termos de viabilidade (política, técnica e administrativa) e de factibilidade, exequibilidade. Assim, definiram-se como itens para a análise factual: I- Descrição do processo de preparação dos programas; II- Descrição de princípios e diretrizes para a gestão governamental;
III- Descrição de análise de conjuntura política; IV- Descrição de análise contextual sobre problemas municipais; V- Descrição de análise sobre situação ou prioridades de saúde no município; VI- Descrição propositiva para estratégias governamentais para o setor de saúde; VII- Descrição de termos de viabilidade para as propostas apresentadas (no item VI); VIII- Descrição de termos de exequibilidade e/ ou factibilidade para as propostas apresentadas (no item VI).

Uma aferição panorâmica acerca da existência desses itens nos programas de governo analisados está apresentada no quadro 1. Por essa aferição, observou-se que, na maior parte dos programas registrados, não constavam alusões ou descrições sobre os termos de viabilidade (governabilidade política; viabilidade técnica/tecnológica ou administrativa e financeira), de factibilidade e de exequibilidade para as propostas apresentadas, o que seria esperado para tal tipo de documento programático. Mesmo as estratégias setoriais de saúde estavam apresentadas mais sob a forma de diretrizes genéricas do que, propriamente, estratégias institucionais, administrativas e programáticas.

Quadro 1. Aferição sobre a descrição de itens identificados na análise de programas de governos apresentados por coligações e partidos políticos concorrentes no primeiro turno das eleições municipais de São Paulo (SP) e Rio de Janeiro (RJ) em 2016

\begin{tabular}{|c|c|c|c|c|c|c|c|c|c|}
\hline $\mathbf{M}$ & Coligação/Partido & $\mathbf{I}$ & II & III & IV & $\mathbf{v}$ & VI & VII & VIII \\
\hline \multirow[t]{11}{*}{ SP } & $\begin{array}{l}\mathrm{PSDB} / \mathrm{PPS} / \mathrm{PV} / \mathrm{PSB} / \mathrm{DEM} / \mathrm{PMB} / \mathrm{PHS} / \mathrm{PP} / \mathrm{PSL} / \mathrm{PT} \text { do B/ } \\
\mathrm{PRP} / \mathrm{PTC} / \mathrm{PTN}\end{array}$ & $x$ & $x$ & & & & $x$ & & \\
\hline & $\mathrm{PT} / \mathrm{PC}$ do B/PR/PDT/PROS & $x$ & & $x$ & $x$ & $x$ & $x$ & & \\
\hline & PRB/PSC/PTB/PEN & & $x$ & & $x$ & $x$ & $x$ & & \\
\hline & $\mathrm{PMDB} / \mathrm{PSD}$ & & $x$ & & & & $x$ & & \\
\hline & $\mathrm{PSOL} / \mathrm{PCB}$ & $x$ & $x$ & $x$ & $x$ & $x$ & $x$ & & \\
\hline & SD & $x$ & $x$ & & & & $x$ & & \\
\hline & REDE & $x$ & $x$ & & $x$ & $x$ & $x$ & & $x$ \\
\hline & PRTB & & & & & & $x$ & & \\
\hline & PSDC & & $x$ & & & & $x$ & & \\
\hline & PSTU & & $x$ & $x$ & & & $x$ & & \\
\hline & PCO & & & $x$ & & & $x$ & & \\
\hline
\end{tabular}




\begin{tabular}{|c|c|c|c|c|c|c|c|c|}
\hline \multirow[t]{11}{*}{ RJ } & $\mathrm{PRB} / \mathrm{PTN} / \mathrm{PR}$ & & $x$ & & & & $x$ & \\
\hline & $\mathrm{PSOL} / \mathrm{PCB}$ & & $x$ & $x$ & $x$ & $x$ & $x$ & \\
\hline & $\begin{array}{l}\mathrm{PMDB} / \mathrm{PDT} / \mathrm{PP} / \mathrm{PTB} / \mathrm{PSL} / \mathrm{SD} / \mathrm{DEM} / \mathrm{PROS} / \mathrm{PHS} / \mathrm{PMN} / \\
\mathrm{PEN} / \mathrm{PSDC} / \mathrm{PTC} / \mathrm{PT} \text { do B/PRTB }\end{array}$ & & & & $x$ & $x$ & $x$ & $x$ \\
\hline & PSC/PRP & & $x$ & $x$ & $x$ & $x$ & $x$ & \\
\hline & $\mathrm{PSD} / \mathrm{PSB} / \mathrm{PMB}$ & & $x$ & $x$ & $x$ & $x$ & $x$ & \\
\hline & PSDB/PPS & $x$ & $x$ & $x$ & $x$ & $x$ & $x$ & \\
\hline & $\mathrm{PCdoB} / \mathrm{PT}$ & $x$ & $x$ & $x$ & $x$ & $x$ & $x$ & \\
\hline & REDE/PV/PPL & & $x$ & & & & $x$ & \\
\hline & NOVO & & & & & & $x$ & \\
\hline & PSTU & & $x$ & $x$ & & & $x$ & \\
\hline & PCO & & & $x$ & & & $x$ & \\
\hline
\end{tabular}

Fonte: Tribunal Superior Eleitoral, $2016^{19}$

M: Município; I- Descrição do processo de preparação dos programas; II- Descrição de princípios e diretrizes para a gestão governamental; III- Descrição de análise de conjuntura política; IV- Descrição de análise contextual sobre problemas municipais; V- Descrição de análise sobre situação ou prioridades de saúde no município; VI- Descrição propositiva para estratégias governamentais para o setor de saúde; VII- Descrição de termos de viabilidade para as propostas apresentadas (no item VI); VIII- Descrição de termos de exequibilidade e/ou factibilidade para as propostas apresentadas (no item VI).

Havia a pretensão de análise distintiva acerca dos discursos práticos proferidos nos documentos programáticos, derivando na caraterização de tipos e termos tematizados acerca de viabilidade (política, técnica, administrativa), de factibilidade e de eficácia das proposições eleitorais, entretanto, constatou-se a inexistência de tais considerações. Os proferimentos registrados nos programas eleitorais de saúde analisados não eram propriamente discursos práticos, mas discursos genericamente prescritivos, cujas expectativas de validade não poderiam posteriormente ser confirmadas, legitimadas ou refutadas, pelo menos, em termos dimensionáveis, procedimentais e teleológicos.

Constatada a inexistência de discursos práticos nos proferimentos analisados, buscou-se a explicação de significados dos discursos normativos (lógica intensiva) e a análise de seu sentido contextual, com destaque na caracterização de pretensões normativas e em tipos de ênfase propositiva (figura 1):

a) medidas de controle (principalmente, de gastos públicos), regulação, ajustes administrativos e agenciamentos (para instituições de direito privado) para o setor de saúde;

b) reformas genoestruturais mais abrangentes (principalmente, em perspectiva de estatizações), contudo, sem proposições de reformas ou medidas específicas de abrangência setorial (inclusive de saúde);

c) inovações em reformas e medidas de maior participação social e gestão participativa, contudo, com exiguidade de proposições para reformas ou medidas de abrangência setorial de saúde;

d) discursos pautados em aspectos aparentes de problemáticas sociais (inclusive de saúde), ausência de proposições estratégicas e programáticas para quaisquer setores governamentais, ênfase na 'competência' individual dos postulantes aos cargos de prefeitos(as) municipais.

Essa tipificação levou em conta analogias intertextuais e convergências de sentidos, 
decorrentes de teores discursivos constantes nos programas eleitorais. Tipos que não podem ser atribuídos isoladamente a determinadas candidaturas porque, em muitos casos, foram identificadas combinações e interveniências em um mesmo texto programático.

Figura 1. Esquema interpretativo para pretensões discursivas identificadas na análise de propostas eleitorais para o setor governamental de Saúde. Municípios de São Paulo (SP) e Rio de Janeiro (RJ), eleições municipais de 2016

Ênfase em problemas e proposições estratégicas para controlé, regulação, ajustes e agenciamentos administrativos e gerenciais no setor de saúde.

nfase em problemas e reformas macroestruturais

(macroeconômicas, estatizantes) mais abrangentes. Exiguidade de estratégias institucionais, setoriais de saúde. participação e gestão participativa.

C Exiguidade de proposições de estratégias institucionais, setoriais de saúde.
PERFIL DISCURSIVO COM PRETENSÕES DISTINTIVAS AO ESTEREÓTIPO DA 'POLÍTICA', DOS 'POLÍTICOS' E DOS PARTIDOS POLÍTICOS
O 'gestor', o 'zelador', o

'empreendedor' no lugar do

'político convencional'.
O 'partido empresarial', o 'partido inovador' no lugar do 'partido convencional'.

\section{PERFIL DISCURSIVO COM PRETENSÕES DEMARCATÓRIAS SOBRE NECESSIDADE DE MUDANCCAS ESTRUTURAIS}

Torna-se necessária a mudança do sistema social sob a égide estatal.

A estatização de todos os serviços de saúde é a 'solução' para a problemática do setor. sintomáticos da problemática de saúde. Ausência de proposições

D estratégicas sociais, institucionais para quaisquer setores (inclusive saúde).
PERFIL DISCURSIVO PERSONALISTA, COM PRETENSÕES PRAGMÁTICAS AD HOC

O 'amigo do povo', que conhece e vai resolver as mazelas dos serviços de saúde.
A gestão 'experiente', que sabe simplificar e resolver tudo da melhor forma, a seu modo.

Fonte: Elaboração própria, a partir da análise dos programas eleitorais disponibilizados pelo Tribunal Superior Eleitora|19

Considerada a tipificação de pretensões normativas interpretadas na análise hermenêutica, principalmente a partir do item descritivo de princípios e diretrizes para a gestão governamental, buscou-se a caracterização de perfis discursivos correlatos, com destaque para aspectos distintivos.
Correlata ao discurso com ênfase em propostas eleitorais para medidas de controle, regulação, ajustes administrativos e agenciamentos para o setor de saúde (a), caracterizou-se uma pretensão distintiva para com as imagens estereotipadas ou estigmatizadas acerca da 'política', dos 'partidos políticos' e 
dos próprios 'políticos'. A conotação predominante nos documentos programáticos assim classificados realçava o perfil dos candidatos não como 'políticos', mas como 'gestores', 'empreendedores' ou 'zeladores' da administração pública. Principalmente nos programas eleitorais de partidos políticos criados mais recentemente (como a 'Rede Sustentabilidade' e o 'Partido Novo'), havia destaque em tal distinção, apresentando as candidaturas e proposições eleitorais como inovações em termos organizacionais, de dinâmicas relacionais ou com novas formas de gestão partidária (principalmente, em racionalidade e regência mais 'empresarial'). Conforme já descrito, uma característica proeminente neste perfil discursivo é a de que os problemas identificados no setor público de saúde estavam definidos predominantemente como de natureza e caráter gerenciais. Assim, as proposições estratégicas de governo estavam pautadas principalmente por ajustes e regulações com o propósito de melhorar a eficiência institucional.

Correlato ao discurso com ênfase em propostas eleitorais para reformas genoestruturais mais abrangentes, mas sem proposições de reformas ou medidas específicas para o setor de saúde (b), caracterizou-se um perfil de discurso eleitoral no qual os programas destacaram propostas de mudanças na política macroeconômica, com prováveis repercussões nas políticas de saúde, mas, em sua maior parte, estiveram fora da governabilidade de âmbito municipal. Preconizou-se, também, a estatização exclusiva dos serviços de saúde nos municípios. Perfil discursivo, cuja conotação discursiva tendeu a ser mais demarcatória, em sentido abrangente de reforma de Estado, com realce para proferimentos genéricos acerca de mudanças estruturais-sociais e a exiguidade de proposições estratégicas institucionais específicas para o setor de saúde.

Correlato ao discurso com ênfase em propostas eleitorais para a inovação e o incremento de estratégias de maior participação social e gestão participativa (c), caracterizou-se um perfil discursivo com pretensão de ênfase em inovações institucionais para aumentar a participação de cidadãos no fomento à democratização de políticas públicas e, com menos destaque, em processos de gestão participativa de governo. Embora tal ênfase tenha sido anunciada como diretriz estratégica, não se observou o alinhamento ou o detalhamento de estratégias sociais específicas para viabilizar tais inovações, tampouco a proposição de estratégias institucionais e setoriais específicas de saúde.

Correlato ao discurso eleitoral pautado em aspectos genéricos de problemáticas sociais e de ênfase na 'competência' individual dos postulantes aos cargos eleitorais (d); caracterizou-se um perfil discursivo de cunho mais personalista, no qual os candidatos enfatizam a problemática da saúde no município, a partir de fenômenos mais aparentes (demora para atendimentos, filas de espera, falta de vagas para internações etc.), e evocam suas 'qualidades' pessoais (experiência de vida e de 'gestão', 'competência', confiabilidade etc.) para 'resolver' tais dificuldades. Em tal perfil discursivo, não foi possível identificar proposições de estratégias governamentais (institucionais, administrativas, programáticas) para o setor público de saúde, mas uma mensagem subliminar de que o voto na candidatura implicaria em uma relação de confiança, além de na delegação de poder, para que os candidatos 'resolvessem os problemas' ao seu modo, ad hoc.

\section{Discussão}

Na discussão estão enfatizadas as perspectivas de hermenêutica dialógica e de mediação, visando à (re)constituição de uma lógica de sentido intertextual e contextual.

A constatação primordial é a de que buscamos inicialmente analisar o que não havia: discursos práticos, em seus termos propositivos de viabilidade, factibilidade e eficácia.

Conforme referido na introdução, espera-se que a atuação de candidaturas e os seus discursos em disputas eleitorais tenham motivações persuasivas, típicas de processos 
concorrenciais. Entretanto, torna-se necessário um melhor entendimento sobre os nexos, interveniências e consequências entre tal aspecto naturalizado e as expectativas próprias de um determinado jogo social: o ‘jogo democrático' das proposições políticas de governo, das expressões programáticas e das representações de interesses em disputa pelo poder governamental.

Para buscar um melhor entendimento acerca do foco de investigação, discursos práticos em determinados contextos e circunstâncias eleitorais, poder-se-ia tomar como referências de análise as teorias sobre competências e ações sociais. Particularmente, a competência e ação definida como teleológica ${ }^{16}$, mais pertinente em se tratando de expectativas e proposições programáticas de viabilidade, eficácia e factibilidade.

Entretanto, identificaram-se discursos eleitorais com conotações mais normativas (nos discursos escritos analisados) e dramatúrgicas (nas performances em veículos midiáticos, como rádio e televisão).

É importante destacar que as (inter)ações dramatúrgicas possuem grande relevância na disputa por hegemonia ideológica porque tendem a induzir naturalizações perceptivas, ideativas na constituição de 'sensos comuns' ${ }^{\text {’6 }}$. A partir de melhor competência dramatúrgica ou da maior disponibilidade de mídias, a disseminação e a 'naturalização' de determinadas mensagens, diretas ou indiretas (subliminares), tende a produzir hegemonia ideológica.

Se nas (inter)ações dramatúrgicas midiáticas podem ocorrer diversas formas de linguagens expressivas, verbais e não verbais, no caso da linguagem escrita e suas mídias, o condicionamento performático leva em conta principalmente as expectativas e projeções acerca do público leitor.

Conforme já descrito, na maior parte dos programas eleitorais analisados não havia o registro de proposições estratégicas mais específicas para o setor de saúde, para além de intencionalidades difusas ou diretrizes genéricas. E, principalmente, não havia registro dos termos de viabilidade e factibilidade, que deveriam ser imprescindíveis, em se tratando da natureza e do caráter dos documentos.

O evidenciamento de lacunas significativas nessas proposições eleitorais poderia induzir uma inferência de que as formulações de tais programas careceram de competência instrumental e estratégica. Entretanto, convém considerar, mesmo que hipoteticamente, que não seria esse o propósito efetivo para a formulação e o registro de tais documentos. Assim, a observância e o exercício de tal racionalidade não seria algo valorizado a ponto de requerer uma formulação pertinente.

É claro que se pode questionar as (in)competências (instrumental e estratégica) em várias das formulações programáticas, uma vez que é possível que muitos dos formuladores sequer tivessem noção de termos prescritivos afins. Contudo, também é possível considerar que, mesmo havendo a disponibilidade para o exercício de tais competências - afinal, grandes partidos políticos e coligações poderiam contratar especialistas para realizar formulações mais elaboradas em termos de discursos práticos -, essa produção não tenha sido devidamente valorizada em função das expectativas acerca de seu público-leitor e, portanto, de seu alcance mais limitado e menor repercussão persuasiva; de sua eficácia eleitoral.

Reitera-se que, em se tratando de documentos programáticos formais, com registro em tribunais eleitorais, a expectativa seria de constarem formulações demonstrativas de competências estratégicas e instrumentais (teleológicas), com proposições estratégicas governamentais e argumentos justificativos acerca de sua viabilidade e factibilidade no período do mandato eleitoral, uma vez que tais registros públicos poderiam servir não somente para a tomada de decisões eleitorais (da parte de eventuais leitores/eleitores) como, também, para o controle público e social em um futuro governo. Afinal, o registro público do programa eleitoral deveria constituir a distinção normativa e prescritiva do que se convenciona denominar, nos termos de senso, como 'promessas de campanha'. 
Nos programas eleitorais analisados, denotou-se uma profusão de apontamentos genéricos, com demarcação de intencionalidades difusas e mais afeitas ao senso comum, em linguagem textual de conotação persuasiva, que seria mais esperada em outras instâncias discursivas e mídias (propagandas de rádio e televisão, comícios etc.).

Seria plausível afirmar hipoteticamente que, parcialmente em função de incompetência formulativa, parcialmente em razão da pouca importância dada a esse tipo de documento, o valor estabelecido para os registros de programas eleitorais tende a ser circunstancialmente formal e figurativo. Estes tendem a ser pouco utilizados posteriormente para alguém aferir ou conferir se os governos eleitos os tomam como referência efetiva para a gestão e as agendas governamentais.

Se o desenvolvimento e o exercício de competências dramatúrgicas é imprescindível para quaisquer jogos sociais, torna-se circunstancialmente ainda mais importante nas disputas eleitorais. Nas últimas décadas, com a institucionalização de determinados jogos e cenários de democracia representativa, tem havido uma maior instrumentalização da propaganda e do marketing (em menor medida, das artes dramáticas) para os jogos de disputa eleitoral e para os jogos de exercício de poder governamental. Empresas, profissionais e equipes de propaganda e marketing se incumbem de aferir, analisar e interpretar predisposições e repercussões de 'sensos comuns', para preparar discursos e performances para os candidatos eleitorais e para os governantes.

É mais usual que os referidos condicionamento e adestramento performáticos, a partir de expectativas de 'sensos comuns', estejam mais afeitos para determinadas mídias (radiofônica, televisiva, instâncias virtuais da Internet etc.) e eventos presenciais (comícios, convenções, reuniões etc.) do que para documentos escritos (como programas com proposições de governo), cujo público leitor é distinto e menor.

Nas disputas eleitorais e em processos de condução governamental, há prioridade para o condicionamento de expressões e mensagens dirigidas para determinados 'sensos comuns', sendo que a divulgação de 'programas de governo' escritos, dada a expectativa de seu alcance e repercussão, tenderia a ser desprestigiada ou mesmo entendida como uma mera formalidade. Claro que as propostas e os programas de governo poderiam ser apresentados, debatidos e divulgados em diversas mídias, além da escrita. Entretanto, dada a preponderância de atos performáticos, os conteúdos propositivos das mensagens tenderiam, em grande medida, a ser substituídos por encenações de maior impacto midiático (aos moldes das propagandas de quaisquer produtos de mercado), no sentido de consumo, repercussão e fixação de mensagens simplificadas.

Em tal tendência, as mensagens eleitorais (ou de governo) não conteriam propriamente expressões de estratégias institucionais (administrativas, programáticas etc.) e de argumentação sobre seus termos de viabilidade (política, técnica, administrativa) ou factibilidade, mas, sobremaneira, expressões de auras carismáticas precondicionadas às expectativas de determinados 'sensos comuns'. As reais motivações, pretensões, intenções e proposições para políticas governamentais em disputa não estariam expressas para o debate e, portanto, para subsidiar as decisões políticas (pelo voto), uma vez que estariam subsumidas pela expressividade performática. Sendo assim, as campanhas e os mandatos eleitorais também estariam reduzidos aos termos de disputas com o mesmo caráter, mediadas por especialistas de mercado - no caso, um 'mercado eleitoral' e de mandatos eleitorais. Seria mais uma forma de captura e redução operada por dinâmicas de mercado, não somente das expressividades e representações de interesses, mas do próprio jogo da democracia representativa.

Busca-se substituir ideologicamente as propostas e discussões estratégicas de governo pelo personagem do 'gestor que não é político'; busca-se substituir a ideia valorativa de um Estado Social com ethos redistributivo pela aura pragmática de um governo-empresarial 
mais 'eficiente'; busca-se substituir o jogo social da democracia representativa pelo jogo social de estratégias mercadológicas de propaganda e marketing.

Em disputas eleitorais sob tais circunstancias, de captura e redução do jogo da democracia representativa pelos jogos dramatúrgicos com hegemonia ideológica mercantil, quais seriam os termos de análise sobre proposições de políticas e estratégias governamentais para o setor público de saúde? Mais particularmente, quais seriam os teores das mensagens (performáticas, persuasivas, propositivas) para políticas públicas em saúde, levando-se em conta principalmente os programas eleitorais escritos?

A ênfase quase exclusiva nos termos de encenações performáticas e midiáticas para disputas eleitorais, com a desconsideração de proposições viáveis para estratégias programáticas de governo e o mascaramento de disposições ideológicas em personagens pretensamente 'pragmáticos' (o 'empresário público', o 'gestor apolítico' etc.), decorre, entre outros fatores, da captura e colonização do poder político pelo poder econômico sob a égide neoliberal, a partir de um processo de 'desdemocratização'20. Em tal contexto, a democracia representativa permanece vigente como simulacro e fachada, pois perde o seu conteúdo substancial e vinculante, sendo substituída por formas de governança intercorporativa e de mercado, em uma era 'pós-democrática'21. Daí, as disputas eleitorais também tendem a ser intermediadas por tal lógica mercantil, com os seus processos e dispositivos correlatos (de empresariamento, de marketing etc.); as candidaturas tendem a ser apresentadas como produtos de consumo rápido para eleitores que não costumam se preocupar em ler e interpretar o que está escrito nos rótulos das embalagens. Consequentemente, a maior parte dos programas de governo registrados pelas candidaturas não tendem a ser efetivamente valorizados, reduzindo-se a meras formalidades rudimentares.

\section{Considerações finais}

Neste estudo, buscou-se, inicialmente, analisar discursos práticos a partir de programas eleitorais para governos municipais, especificamente proposições programáticas concernentes ao setor de saúde. Na ausência de registros desse tipo, optou-se pela caracterização de perfis discursivos de conotação mais normativa e pela formulação de hipóteses acerca do pouco valor atribuído a documentos dessa natureza.

Em função da delimitação de amostra intencional e do método de análise documental, o estudo realizado apresentou limitações substanciais. Por exemplo, não houve enfoque e análises acerca de aspectos preliminares e contextuais dos processos de formulação para os programas eleitorais em questão. Espera-se que outros estudos sobre essa temática possam ser realizados, de modo a produzir mais explicações e melhores evidências sobre processos dessa natureza.

\section{Colaboradores}

Garcia, MR (0000-0002-6776-5628)*, Miranda AS (0000-0001-8947-9676)* contribuíram conjuntamente para a concepção, o planejamento e a realização do estudo; e para a análise dos discursos, assim como para a elaboração do rascunho e a aprovação da versão final do manuscrito. 


\section{Referências}

1. Conselho Federal de Medicina. "Opinião dos brasileiros sobre $\mathrm{o}$ atendimento na área de Saúde”. [internet]. [acesso em 2016 jun 12]. Disponível em: http://portal.cfm.org. br/images/PDF/apresentao-integra-datafolha203.pdf.

2. Veiga LF, Souza NR, Cervi EU. Da expectativa de vitória à derrota: estratégias discursivas do PT em Curitiba e Porto Alegre em 2004. Rev. Bras. Ciênc. Polít. [internet]. 2011 jul-dez [acesso em 2016 jul 12]; 6:99-135. Disponível em: http:// www.scielo.br/scielo.php?script=sci_arttext\&pid $=$ S0103-33522011000200005.

3. Tarouco GS. Partidos de oposição nos estados: 0 ambiente da competição na arena eleitoral. Cad. CRH. 2012 set-dez; 25(66):573-585.

4. Barros GPH. O senador e o bispo: as estratégias de construção identitária nas eleições municipais cariocas de 2004. Relig. Soc. 2012; 32(1):97-129.

5. Moura RKT. (Des)Construindo o discurso eleitoral: o primeiro turno das eleições municipais majoritárias em Curitiba no ano 2000. Rev. Sociol. Polít. 2001 jun; 16:67-95.

6. Guarnieri F. Voto estratégico e coordenação eleitoral testando a Lei de Duverger no Brasil. Rev. Bras. Ci. Soc. 2015 out; 30(89):77-92.

7. Pinto CRJ. Elementos para uma análise de discurso político. Rev. Barbarói. 2006; 24(1):78-109.

8. Machado M. A retórica da reeleição: mapeando os discursos dos Programas Eleitorais (HGPE) em 1998 e 2006. Opin. Pública. 2009 jun; 15(1):159-189.

9. Mari H. Atos de fala no discurso de candidatos à Prefeitura de Belo Horizonte: Análise da promessa e da crítica. In: Machado IL, organizador. Teorias e práticas discursivas. Estudos em análise do discurso. Belo Horizonte: Carol Borges; 1998. p. 227-248.

10. Telles HS. Da TV ao eleitor: o sinuoso caminho dos discursos de campanha. Em Debate. 2009 out; 1(2):5-11.
11. Figueiredo M, Aldé A, Dias H, et al. Estratégias de persuasão eleitoral: uma proposta metodológica para o estudo da propaganda eleitoral. Opin. Pública. 1997 nov; 4(3):182-203.

12. Goldsmith SB. Political party platform health planks: a mechanism for participation and prediction. Am. J. Public Health. 1973 jul; 63(7):594-601.

13. Silver GA. Medical politics, health policy. Party health platforms, promise and performance. Int. J. Health Serv. 1976; 6(2):331-343.

14. Rivera JU. Agir Comunicativo e Planejamento Social: uma crítica ao enfoque estratégico. Rio de Janeiro: Fiocruz; 1995.

15. Freitag B, Rouanet SP. Habermas. 3. ed. São Paulo: Ática; 1993.

16. Habermas J. Teoria de la Acción Comunicativa. Madri: Taurus Humanidades; 1987.

17. Ricoeur P. Teoria da Interpretação. Lisboa: Edições $70 ; 1987$.

18. Testa M. Saber em Salud. Buenos Aires: Lugar Editorial; 1997.

19. Tribunal Superior Eleitoral. Divulgação de Candidatura e Contas Eleitorais. [internet]. [acesso em 2017 jan 23]. Disponível em: http://divulgacandcontas.tse. jus.br/divulga.

20. Dardot P, Laval C. A nova razão do mundo: ensaio sobre a sociedade neoliberal. São Paulo: Boitempo; 2016.

21. Casara RRR. Estado pós-democrático, neo-obscurantismo e gestão dos indesejáveis. Rio de Janeiro: Civilização Brasileira; 2017.

Recebido em 10/01/2018

Aprovado em 04/07/2018

Conflito de interesses: inexistente

Suporte financeiro: não houve 